Filol. linguíst. port., São Paulo, 15(1), p. 155-178, Jan./Jun. 2013.

DOI: 10.11606/issn.2176-9419.v15i1p155-178.

\title{
O continuum de não-atribuição de causalidade na Crônica Geral de Espanha de 1344
}

\author{
The continuum of non-attribution of causality in Crônica Geral \\ de Espanha de 1344
}

\author{
Maria Claudete Lima \\ Universidade Federal do Ceará (UFC), Brasil \\ claudetelimaster@gmail.com
}

Resumo: Este trabalho analisa, num enfoque cognitivofuncional, as construções passivas, médias e impessoais no português arcaico, com o fim de demonstrar que fazem parte de um continuum de causalidade. Considera que o traço comum a essas construções é a não-atribuição de causalidade, e que estas construções refletem diferentes conceitualizações de um evento. 1061 ocorrências, retiradas da Crônica Geral de Espanha de 1344, foram analisadas quanto a fatores semânticos, como a saliência cognitiva do Afetado e do Causativo, o traço [animado], a transitividade, e depois graduadas quanto ao grau de transitividade e causalidade. Os resultados apontaram que a média é a mais prototípica das construções de não-atribuição de causalidade, por ser a que apresenta causativo menos saliente e menor grau de transitividade. A passiva caracterizou-se como menos prototípica por seu Causativo ser frequentemente evocado e apresentar maior grau de transitividade. Do mesmo modo, a impessoal, cujo causativo é frequentemente inferível, manifestouse como mais causativa e mais transitiva que a média, todavia menos que a passiva.

Palavras-chave: passiva, média, impessoal, causalidade.

Abstract: Based on a cognitive-functional approach, this work
analyzes the passive, middle and impersonal constructions in
Archaic Portuguese, in order to demonstrate that they form a
causality continuum. The present research, thus, claims that the 
common feature of these constructions is the non-attribution of causality, and that they represent different conceptualizations of an event. Semantic aspects such as cognitive salience of Affected and of Causative, animacy and transitivity were analyzed in 1061 occurrences of these construction in "Crônica Geral de Espanha de 1344."They were then divided according to transitivity and causality degrees. The results indicate that the middle construction is the most prototypical of the constructions of non-attribution of causality, because it presents the least salient causative and the lowest degree of transitivity. The passive was characterized as the least prototypical construction because its causative is commonly evoked and it presents a higher degree of transitivity. Impersonal construction, whose causative is frequently inferable, was characterized as more causative and more transitive than the middle construction, but, less causative and less transitive than the passive.

Keywords: Passive voice, middle voice, impersonal voice, causality.

\section{Introdução}

Este trabalho analisa as construções passivas, impessoais e médias em um período remoto da língua portuguesa, o final do século XIV, partindo do domínio funcional não-atribuição de causalidade, com o fim de demonstrar que fazem parte de uma escala de causalidade, o que explica as afinidades semântico-discursivas encontradas em análises de tais construções no português atual.

Ao considerar como traço comum a tais construções a não-atribuição de causalidade, afirma-se que são recursos à disposição do falante para codificar eventos sem a intervenção de um agente/causativo por diversas razões semântico-pragmáticas: por o agente/causativo simplesmente não existir, caso dos eventos espontâneos; por o falante não desejar mencioná-lo, caso dos chamados eventos pseudo-espontâneos; ou por a entidade controladora do evento ser desconhecida ou óbvia demais.

Apoiado no enfoque cognitivo-funcional, em autores como Hopper e Thompson (1980), Kemmer (1993), Langacker (1987, 1991), Givón (1993, 2001, 2005) e Camacho (2002, 2003, 2006), o pressuposto dessa pesquisa, que analisou 1061 ocorrências, é que as construções passivas, impessoais e médias codificam a não-atribuição de causalidade em variados graus, conforme a saliência do causativo e o grau de transitividade de cada construção. 
Este trabalho acha-se dividido em três partes. Inicialmente, aborda-se a noção de causalidade e de não atribuição de causalidade na linguística cognitivo-funcional. Em seguida, caracteriza-se brevemente o corpus e apresentam-se os procedimentos de análise. Por fim, discutem-se, qualitativa e quantitativamente, os resultados da análise das ocorrências e apresenta-se a escala de causalidade.

\subsection{A noção de causalidade}

No âmbito da linguística cognitiva, a causalidade é considerada uma "construção mental, apoiada na experiência e inclui vários conceitos causais prototipicamente estruturados" (SILVA, 2004, p.576) ${ }^{1}$. Para representar esse construto, vários modelos foram propostos, entre os quais, o modelo bola de bilhar de Langacker (1991), o qual descreve a causalidade como um Modelo Cognitivo Idealizado arquetípico, que dá conta de nossa visão de mundo como povoado de objetos discretos que se movem num espaço, entram em contato uns com os outros e participam de interações energéticas. O movimento dos objetos é comandado por energia (ou força), que alguns retiram de recursos internos e outros recebem do exterior. Assim, além da força ou energia (interação), são elementos desse modelo: o espaço (movimento), o tempo (mudança) e a substância material (objetos).

Esta visão de causalidade representa uma cadeia de ação: um objeto faz forte contato com outro, resultando em transferência de energia. O segundo objeto é dirigido em contato com outro, resultando de novo em transferência de energia e assim indefinidamente, até que a energia se acabe ou nenhum contato seja feito. O núcleo da cadeia é o objeto inicial, e a cauda é o objeto final. Em cadeias de ação mais simples, o núcleo e o fim interagem sem intermediários, há apenas dois objetos participantes. A figura abaixo, reproduzida de Langacker (1987, p.283), representa uma cadeia de ação:

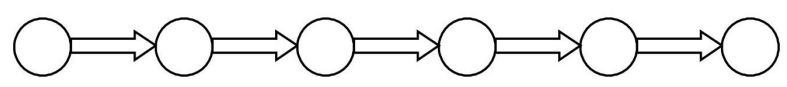

Fig. 1: cadeia de ação (LANGACKER, 1987).

Essa conceitualização da experiência como uma rede causal se manifesta na linguagem, como na frase (1).

${ }^{1}$ [causation] is a mental construction, grounded in experience and includes various causal concepts prototypically structured (SILVA, 2004:p. 576). 
(1) Pedro abriu a porta.

A frase (1) é a codificação de um evento canônico causativo, em que há dois participantes, um dos quais um agente arquetípico, "pessoa que voluntariamente inicia uma atividade física, resultando, através de contato físico, numa transferência de energia a um objeto externo" ${ }^{2}$, e o outro, um paciente também arquetípico, "objeto inanimado que absorve a energia transmitida via contato físico iniciado fisicamente e, por isso, experimenta uma mudança de estado"33.

Por ser a noção de causalidade central em nosso modo de perceber e conceber o mundo, é mais natural conceitualizar eventos de mudança com referência à interação energética, cuja manifestação linguística, como vimos em (1), é a oração transitiva canônica. Há, todavia, conceitualizações em que a mudança é vista como não provocada. Trata-se da conceitualização de eventos espontâneos, em que o falante concebe o evento se dando naturalmente por uma força interna à entidade ou sobrenatural. Esta conceitualização se encontra gramaticalizada em português (e em outras línguas) na construção média, uma construção intransitiva com apenas um participante, em que, às vezes, aparece um marcador médio, o clítico se, que reforça a responsabilidade do único participante no evento, como em a ferida (se) fechou (sozinha) ou a criança cresceu.

Concebida a mudança como resultado de uma intervenção, ou seja, como provocada, muitas opções se colocam ao falante que, a depender da focalização, pode representar o evento como se dando espontaneamente ou como resultado de uma causa que não conhece ou simplesmente não deseja expressar, seja por isenção de responsabilidade ou por irrelevância. Defendemos que as diferenças entre as várias conceitualizações possíveis será uma diferença de grau. Concebendo a mudança como provocada e a entidade provocadora sendo percebida e conhecida, o falante pode escolher codificá-la ou não. No primeiro caso, tem à sua disposição, em português, a depender da perspectiva adotada, a construção transitiva causativa, a chamada voz ativa, como o vento/Pedro abriu a porta ou a construção passiva agentiva, a porta foi aberta

\footnotetext{
${ }^{2}$ The arquetypal agent is a person who volitionally initiates physical activity resulting, through physical contact, in the transfer of energy to an external object (Langacker, 1991, p.285).

${ }^{3} \mathrm{Na}$ inanimate object that absorbs the energy transmitted via externally initiated physical contact and thereby undergoes an internal change of state (Langacker, 1991, p.285).
} 
[por Pedro]/[pelo vento]. A diferença entre as duas construções, portanto, é uma questão de focalização: causativo na ativa e paciente na passiva.

Todavia, o falante pode optar por não codificar a entidade provocadora da mudança, seja por desconhecê-la, seja por ser genérica demais, seja por isentá-la de responsabilidade, seja por ser irrelevante para os propósitos discursivos. As construções impessoal, passiva e média atendem às diversas conceitualizações possíveis nesses casos e divergem quanto ao grau de apagamento da entidade provocadora. Tais construções, tratadas por Givón (1993) como de-transitivas, são descritas na literatura linguística de modo geral como desvios da oração ativa prototípica, quer por transformações, quer por derivações lexicais, quer por redução de valência, quer por perda de propriedades sintático-semânticas.

Para nós, nenhuma dessas propostas é satisfatória, pelas seguintes razões: (a) tais construções não são todas "modos diferentes de dizer a mesma coisa" - são, na verdade, codificações de diferentes conceitualizações, como já argumentamos; (b) nem todas se relacionam ao evento transitivo prototípico - a média espontânea, como a grama cresceu, não corresponde a nenhuma construção ativa ${ }^{*} X$ cresceu a grama, como alegam a respeito dos pares $\mathrm{X}$ abriu a porta/a porta abriu; (c) elas fazem parte de um continuum de causalidade, cujos extremos são a transitiva-causativa (construção mais causal, não analisada aqui) e a média espontânea (menos causal), como pretendemos demonstrar ao longo deste trabalho, com base no resultado da análise de 1061 ocorrências.

\section{Metodologia}

Para analisar as estratégias de não-atribuição de causalidade, selecionamos como corpus a Crônica Geral de Espanha de 1344 (CGE), obra historiográfica da Península Ibérica, que traz informações referentes ao uso da língua no português arcaico, fontes genealógicas dos nobres daquele período e fatos históricos recheados de fantasias, realidades, personagens lendários e episódios sobrenaturais. A escolha deste corpus do século XIV deveu-se à necessidade de investigar a relação entre as construções passiva, impessoal e média em um período remoto da língua portuguesa, vez que análises do português atual demonstraram afinidades semântico-discursivas entre tais construções (cf. CAMACHO, 2002; 2006). Sobre a Crônica, assim se pronuncia Mattos e Silva (1989):

ainda no século XIV, A Crônica Geral de Espanha de 1344, maior monumento histórico do século, organizado pelo Conde Barcelos, tem posição preponderante sobre todos os textos históricos medievais portugueses. Constituída de tradução de fontes latinas, árabes e hispânicas, apresenta também produção originariamente em português (MATTOS E SILVA, 1989, p.30). 
Servimo-nos de uma versão eletrônica, em html, calcada na edição crítica de Luís Filipe Lindley Cintra (1951) e disponibilizada ao público através do Projeto Corpus Informatizado do Português Medieval - CIPM. A edição crítica do texto português da Crónica Geral de Espanha, tese de Doutoramento de Cintra, resultou de um longo trabalho, cuja publicação consta de quatro volumes, em que o primeiro se refere a um estudo minucioso da obra. A versão digitalizada da obra completa também se encontra disponível na Internet através da Biblioteca Nacional Digital (http://purl.pt/index/geral/PT/index.html). Para proceder à edição, Cintra (1951) usou como base o chamado pergaminho $L$, o mais antigo em português, encontrado em Lisboa e situado entre 1410 e 1420.

Com o fim de construirmos uma escala de causalidade baseada em dados quantitativos, analisamos 1061 ocorrências, coletadas dos primeiros 150 capítulos da Crônica. Para tanto, partimos do sentido não-atribuição de causalidade, e categorizamos as ocorrências conforme o tipo de construção que representava. Esta variável assumiu três formas. Primeiramente, as construções foram classificadas num tipo geral: passiva, impessoal e média. Depois, foram reclassificadas mais detalhadamente, de acordo com a codificação formal.

Consideramos passiva 4 a construção formada por ser $+v$-do a que pode se agregar um sintagma preposicionado cujo valor semântico é mais comumente agentivo, ilustrada em (2) e (3).

(2) fora os de Çamora vençudos e e $\sim$ çarrados dentro na cidade. (CGE, $71)^{5}$

(3) E Roma, que soya seer vencedor de todallas gentes, foy vençuda dos Godos. (CGE-81)

\footnotetext{
${ }^{4}$ A passiva é o único tipo que não apresenta subclassificação formal. A distinção passiva com agente e passiva sem agente não nos serviria, uma vez que estamos considerando o papel geral Causativo que pode figurar também nas médias.

${ }^{5}$ Os trechos mantêm a ortografia do corpus. Os números entre parênteses referem-se ao capítulo de onde foi retirada a passagem. Eventualmente, oferecem-se glosas em rodapé. A construção em foco encontra-se em itálico.
} 
A construção média, como dito na seção anterior, constitui a codificação do construto absoluto, em que o tema é a entidade sob mudança e não há nenhuma referência à entidade causadora. Recebe duas codificações verbais: a construída na base de um verbo na forma ativa, ou seja, conjugado na forma simples ou em perífrases com ter/haver, acompanhado ou não do clítico se; e a construída com verbos de mudança de estado, como ficar, tornar-se, ser (com valor de ficar) e um adjetivo ou particípio. Ao primeiro tipo, denominamos média clítica ou não-clítica, conforme seja ou não acompanhado do clítico, como exemplificado em (4) e (5), respectivamente. Ao segundo tipo, chamamos média perifrástica, ilustrada em (6-8).

(4) as hervas nu ca se secam tanto que falleça pasto. (CGE-15)

(5) e muy boos prados que no secam em nem hu $\sim \mathrm{u} \sim$ tempo. (CGE-41)

(6) E o bispo e os sancrista a a es da igreja ficaron muy spantados. (CGE150)

(7) ficarom os Godos muy louça a os. (CGE-81)

(8) E elle, quando esto vyo, foy sobejamente espantado... (CGE-124)

As impessoais constituem as tradicionalmente consideradas orações de sujeito indeterminado, que chamamos de impessoais não-clíticas, e a oração passiva sintética, que chamamos de impessoal clítica, ilustradas em (9) e (10), respectivamente.

(9) acham hy rastro das cousas antigas muy maravylhosas... (CGE-21)

(10) e delas em outras maneiras que se podem levar... (CGE-72)

Cada ocorrência foi analisada quanto a variáveis referentes ao Afetado ${ }^{6}$, ao Causativo ${ }^{7}$ e à Construção, que passamos a descrever.

\footnotetext{
${ }^{6}$ Optamos por chamar Afetado (Af) à entidade que experiencia a mudança, uma vez que será o traço comum à entidade afetada por uma mudança de estado física ou emocional.

7 Tratamos a entidade provocadora por Causativo, um traço comum aos papéis Agente, Instrumento e Causativo, que pode se manifestar como uma entidade concreta ou abstrata, animada ou inanimada.
} 


\subsection{Variáveis referentes ao Afetado}

A saliência cognitiva do SN que representava o Afetado foi medida em graus, conforme três variáveis: o traço [+animado], a definitude e o número do SN. Atribuímos pontos a cada propriedade do seguinte modo:

a) quanto ao número do $\mathrm{SN}$ :

plural $/$ coletivo $=0$

singular $=1$;

b) quanto à definitude:

indefinido $=0$

definido $=1$;

c) quanto ao traço [+animado]:

animado humano $=3$

animado não-humano $=2$

inanimado concreto $=1$

inanimado abstrato $=0$.

Aplicadas essas medidas, obtivemos uma escala de saliência do Afetado das construções, que variou de 0 a 5 graus, ou seja, da saliência nula (grau 0) a altíssima saliência (grau 5). Essa escala foi simplificada depois para uma escala quartenária, em que mantivemos os extremos como alta saliência (grau 5) e saliência nula (grau 0) e agrupamos os graus intermediários em dois: média saliência (graus 3 e 4) e baixa saliência (graus 1 e 2).

\subsection{Variáveis referentes ao Causativo}

Foram analisadas quatro variáveis: a identificabilidade do Causativo; o tipo de causa; o traço [+animado] e a saliência do Causativo.

Para avaliar a identificabilidade do causativo, servimo-nos de categorias concernentes ao estatuto informacional (cf. PRINCE, 1981) que indicam a acessibilidade do causativo no contexto, propondo os seguintes fatores: (a) evocado anaforicamente; (b) evocado cataforicamente; (c) evocado situacionalmente; (d) inferível; (e) expresso na oração; (f) não-identificável.

O tipo de causa serviu de base para a medida de saliência do causativo, baseada no grau de distinguibilidade dos participantes (cf. KEMMER, 1993). Consideramos os seguintes tipos de causas: 
O continuum de não-atribuição de causalidade...

The continuum of non-attribution of...

a) externa concreta percebida: o Causativo é concreto e representado.

(11) esta villa foy feyta d'Alaquiny e fundoua Abraz.(CGE-25)

b) externa concreta identificável: o Causativo é concreto e inferível pelo Universo Cultural.

(12) dous ryos que chamam a hu u Doiro e outro Mynho. (CGE-4)

c) externa concreta não-identificável: pela natureza do verbo, identificase que o Causativo é concreto, mas não é possível identificá-lo especificamente.

(13) E entendeu per seu saber que ally avya de seer poboada hu a grande cidade mais que no a pobraria elle. (CGE-12)

d) externa abstrata percebida: constitui eventos que atuam como Causativos e estão representados.

(14) E chegou o feyto delle a Pompeo tanto per que ouvera de seer destroyda Roma. (CGE-72)

e) externa abstrata não-identificável: constitui-se de eventos nãoidentificáveis. A doença, por exemplo, tem uma causa, que pode ser ação da própria natureza (ataque de peste, por exemplo) ou mesmo de uma entidade divina (como se cria, na época). Consideramos abstrato pelo caráter de evento.

(15) estando e aquella cidade de Orlleens, adoeceu e morreo hi de sua morte. (CGE-99)

f) interna percebida: quando o evento é resultado de propriedades internas e o Causativo está representado.

(16) foron aly desmanhados de sede...(CGE-78)

g) interna não-identificável: quando não é possível identificar a causa, mas o contexto permite inferir que não foi provocado por fatores externos, a exemplo da ocorrência de mortes sem menção ao fator provocador, que podia ser agravamento de doenças, velhice etc.

(17) E morreo Tarcos e ficou qua to elle avya a Rotas. (CGE-12) 
h) não-identificável: quando um Causativo é concebível, mas não é possível identificar a natureza externa ou interna, concreta ou abstrata.

$$
\text { seredes mortos e destroydos...(CGE-77) }
$$

i) sobrenatural: quando o evento é atribuído a entidades divinas.

$$
\text { Outrossy em este a no que este milagre foi feito... (CGE-124) }
$$

j) inconcebível: quando o evento é tido como espontâneo.

(20) E amadurecem hy mais toste as arvores que som agras. (CGE-16)

O traço [+animado] do Causativo tem as mesmas categorias da variável aplicada ao Afetado, exceto pelo acréscimo de mais duas. São, portanto, seis as possibilidades: (a) animado humano; (b) animado não-humano; (c) inanimado concreto; (d) inanimado abstrato; (e) divino; (f) não-identificável.

Com base no tipo de causa, medimos a saliência cognitiva do Causativo em graus, conforme a exterioridade e a visibilidade. Assim, uma causa externa concreta percebida tem altíssima saliência. Uma externa concreta identificável tem alta saliência. As causas concretas não-identificáveis e sobrenaturais apresentam média saliência. As abstratas e as internas percebidas apresentam baixa saliência. Por fim, as abstratas não-identificáveis, as internas nãoidentificáveis, e as não-identificáveis apresentam baixíssima saliência. Já as inconcebíveis apresentam saliência nula. Para facilitar o paralelo com a saliência do SN e com o grau de transitividade, adiante exposto, esta variável foi transformada em quartenária: alta (altíssima e alta), média, baixa (baixíssima e baixa) e nula.

\subsection{Variáveis referentes à construção}

Avaliamos a construção globalmente quanto à transitividade. Esta foi medida em graus, conforme seis dos dez parâmetros de Hopper e Thompson (1980). A volição e a potência do agente não foram consideradas, por este nem sempre estar presente nas construções analisadas. A pontualidade e a telicidade foram substituídas pela perfectividade. Também o grau de afetação do Objeto não foi considerado, porque raramente o contexto determina o grau de afetação do SN. Há contextos, como os ilustrados em (21) e (22), em que fica clara a afetação total ou parcial do SN, mas isso não é sistemático.

(21) de que todo foy comydo. (CGE-97) 
(22) se no que e $~$ esta no foy de todo vençudo. (CGE-80)

Por fim, foram estes os aspectos avaliados: (a) $\mathrm{n}^{\mathrm{O}}$ de participantes (um ou mais de um); (b) cinese (ação ou não-ação); (c) polaridade (afirmativa ou negativa); (d) modalidade (realis ou irrealis); (e) individuação; (f) perfectividade. Todos esses parâmetros, à exceção dos dois últimos, foram avaliados conforme apresentados em Hopper e Thompson $(1980)^{8}$.

No que diz respeito à individuação, embora tenhamos partido da proposta dos autores, que apresentam fatores de alta e baixa individuação, para efeito de análise, sistematizamos uma escala de individuação, conforme a saliência cognitiva. Para tanto, conjugamos os fatores da saliência cognitiva, já explicitados, à expressão por nome próprio, simplesmente acrescentandose +1 , quando o SN era assim representado. Disso resultou uma escala de individuação de 0 a 6, exemplificada em (23-29), que, para possibilitar a avaliação da transitividade, foi agrupada numa variável binária, do seguinte modo: (a) individuado: graus 3 a 6; (b) não-individuado: graus 0 a 2 .

a) grau de individuação 6 (próprio - definido - singular - animado humano)

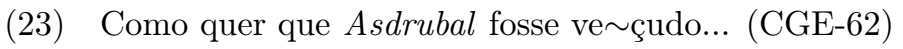

b) grau de individuação 5 (definido - singular - animado humano)

(24) elle era recebido e na corte tam honrradame te... (CGE 72)

c) grau de individuação 4 (definido - plural - animado humano)

(25) E e $\sim$ cabo foro vençudos e mortos os Roma a os. (CGE-66)

d) grau de individuação 3 (definido - singular - inanimado concreto)

(26) o castello de Tortossa he muy bem feyto a maravylha... (CGE-20)

e) grau de individuação 2 (indefinido - singular - inanimado concreto)

(27) avya de seer pobrada hu a muy nobre cidade. (CGE-8)

\footnotetext{
${ }^{8}$ Como sabemos, os autores atribuem a esses fatores graus de transitividade alta ou baixa. Assim, ter mais de um participante é alta transitividade. Do mesmo modo, ser modalidade realis ou ser predicado de ação.
} 
f) grau de individuação 1 (indefinido - plural - inanimado concreto)

(28) e foron em elle feytas muytas boas cousas. (CGE-150)

g) grau de individuação 0 (indefinido - plural - inanimado abstrato)

(29) algu as cousas fossen escriptas dos feytos d'Espanha. (CGE-1)

Quanto à distinção perfectivo e imperfectivo, seguimos a classificação aspectual de Comrie (1978), exemplificada em (30) e (31).

a) perfectivo:

(30) E em esta maneira foy Calez poboada. (CGE-11)

b) imperfectivo:

(31) e de hy o levam a muytas partes. (CGE-20)

Cada ocorrência recebeu um ponto cada vez que continha o fator avaliado (mais de um participante, predicado de ação, afirmativa, realis, individuado, perfectivo), de modo que chegamos a uma escala de transitividade que varia de 0 a 6 graus: altíssima (grau 6), muito alta (grau 5), alta (grau 4), média (grau 3), baixa (grau 2), baixíssima (grau 1), nula (grau 0). Depois, para facilitar a análise, esta foi agrupada numa variável ternária: alta transitividade (graus 5 e 6), média transitividade (graus 3 e 4) e baixa transitividade (graus 0 a 2).

A seguir, apresentamos os resultados encontrados, de modo a deixar entrever as semelhanças e diferenças entre as construções, tidas como partes de um mesmo continuum de causalidade.

\section{Análise dos Resultados}

\subsection{A saliência do Afetado}

Com base na literatura sobre o tema, pressupomos que o Afetado de todas as construções de não-atribuição de causalidade seria inanimado. Os dados mostraram, todavia, com exceção das impessoais, uma predominância de entidades animadas, geralmente humanas, com percentuais de $58 \%$ a $82 \%$.

Entidades animadas são altamente salientes por serem móveis e daí perceptualmente mais proeminentes, o que justifica sua escolha como sujeito 
por constituírem Figura. No caso de serem humanas, são ainda mais salientes, por atraírem a empatia do falante por semelhança.

No caso da passiva, conforme apontou Camacho (2002), a alta incidência de SN sujeitos humanos na passiva no corpus pode-se justificar pela possibilidade de menção do SN agentivo, geralmente humano, que torna possível a atuação da função de perspectivação. Ou seja, diante de dois participantes humanos, escolher uma construção ativa ou passiva pode depender de qual participante se quer perspectivar: o que representa a entidade Causativa ou o que representa a entidade Afetada. Essa escolha, por sua vez, dependerá de fatores pragmáticos, como o grau de topicalidade e identificabilidade das duas entidades. Quando o Causativo tem o traço [+humano] determinado pelo predicado, mas é indefinido ou é referencialmente genérico, a tendência é selecionar como sujeito o Afetado.

No caso das médias, a predominância de entidades humanas se explica pela hierarquia da empatia proposta por Langacker (1991) e reproduzida a seguir:

falante $>$ ouvinte $>$ humano $>$ animal $>$ objeto físico $>$ entidade abstrata

Uma vez que, nas médias, o Causativo, quando representado, é predominantemente inanimado, a escolha do sujeito recai sobre a entidade humana afetada, mais próxima do falante que um evento ou um objeto. Além disso, dentre as construções, as médias, de modo geral, foram as que apresentaram maior frequência de eventos mentais e, nessas construções, diferentemente da passiva e das impessoais, a entidade experienciadora figurava como sujeito, o que justifica também a alta frequência de entidades humanas como sujeitos.

\subsection{O Causativo}

Quanto à identificabilidade do Causativo, hipotetizamos que, excetuando-se o Causativo da média, que seria não recuperável, o Causativo da passiva e da impessoal seria recuperável, variando apenas a fonte de acesso referencial. O Causativo da passiva estaria ancorado no discurso. O da impessoal, no universo cultural.

Os dados mostraram que, de fato, o Causativo da passiva, embora frequentemente omitido na própria oração, é evocado anafórica ou cataforicamente. Já o Causativo da impessoal é predominantemente inferível. O gráfico 1 resume esses resultados. 


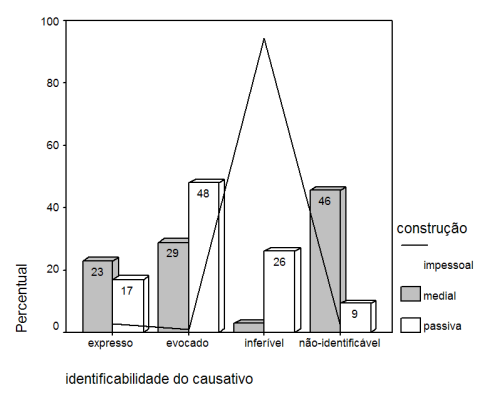

Gráfico 1. Identificabilidade do Causativo das construções.

Vemos no gráfico que, enquanto a passiva e a média (representadas por barras, clara e escura, respectivamente) apresentam várias formas de acesso ao Causativo (expresso, evocado, inferível, não-identificável), a impessoal (representada por uma linha inteira), praticamente, só apresenta o tipo inferível. Já a passiva apresenta $48 \%$ de Causativo evocado no contexto prévio ou posterior. A omissão do Causativo, na passiva é, então, motivada predominantemente por este ser informação velha. Já na impessoal, a motivação da construção é ser o Causativo universal ou estereotipado. Em outras palavras, é o estatuto informacional do Causativo que justifica sua omissão nas construções passiva e impessoal, pelo menos, nos dados analisados, isto é, considerando o fato de ser um texto em prosa histórica do séc. XIV. Seria necessário investigar esta função em outros gêneros, especialmente, aqueles em que a função interpessoal se sobressai, como o gênero teatral, na escrita, e os diálogos, na fala.

Na média, o Causativo é não-identificável em $46 \%$ das ocorrências. Esta alta frequência de Causativo não-identificável sinaliza para um uso motivado por desconhecimento da fonte de energia ou por uma energia interna, que implica numa baixa distinguibilidade dos participantes. O gráfico a seguir, ilustrando os vários tipos de causas, mostra que a média é a construção predominante quando a causação é interna, sobrenatural ou inconcebível. 


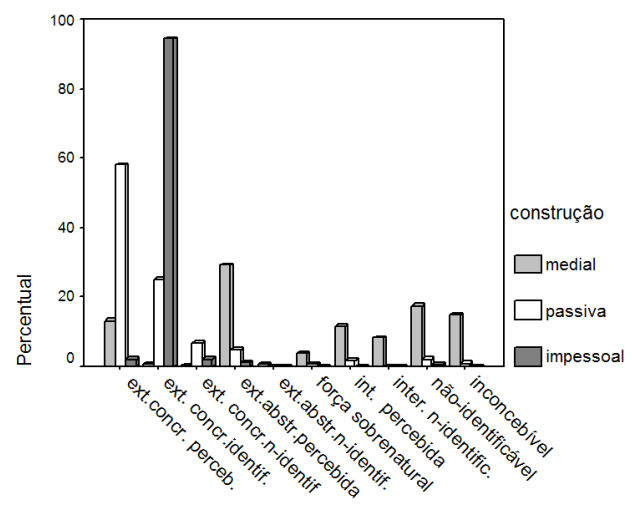

Gráfico 2. Tipo de causas nas construções.

Na causação interna, há uma espécie de sobreposição entre Causativo e Afetado que leva à percepção do evento como não-provocado ou como provocado por forças sobrenaturais não-manipuláveis. Nos eventos espontâneos, codificados predominantemente pela construção média, a noção de causa ligase à substância, no sentido aristotélico, segundo o qual, para compreender a causa, é necessário compreender a razão pela qual uma substância é o que é e não pode ser ou agir diferentemente. É o que vemos claramente na frase (32, em que o evento espontâneo qualhar-se é visto como decorrente da substância da água.

(32) a sua augua ha vyrtude muy estranha que se qualha en pedras. (CGE16)

Na Crônica, eventos espontâneos irrompem sob a forma de milagres, aparições e eventos naturais inexplicáveis. Não é à toa ser a codificação deste maravilhoso preferencialmente a média:

escureceu o sol e a lu $\sim$ a... (CGE-87)

(34) e todos disseron que era mylagre de Deus, ca no sabya $\sim$ onde enchera. (CGE-44)

(35) Mas o Nosso Senhor Jhesu Cristo, a que nom praz dos home e $\sim$ s que obram sem justiça e sen piedade e con sobervha, e ryou o seu ben ave turado martyr Sam Beento, que fora bispo de Letena, aquelle que fora marteyrado e queymado per el rey Unerico, assy como ja ouvystes, e apareceu e vyson ao emperador Justynyano. (CGE-114) 
Na tabela 1, vemos que, das 14 ocorrências em que os eventos são atribuídos explicitamente a forças sobrenaturais, 11 são expressos pela média, o que equivale a 78,6\%. O Causativo da média, quando identificável, é o menos saliente, uma vez que predominam entidades inanimadas e divinas. Por outro lado, a referência a entidades humanas como fonte de energia é praticamente regra categórica na passiva e na impessoal: 87,3\% e 97\%, respectivamente.

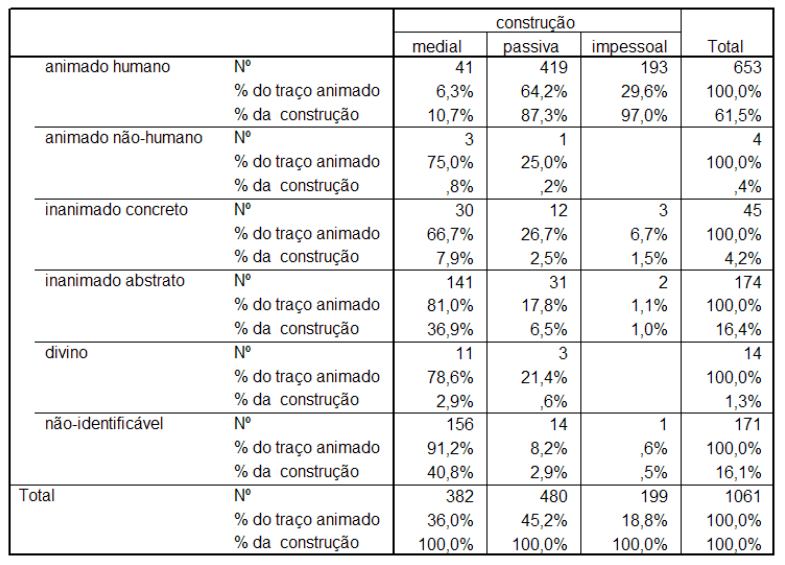

Tabela 1. Traço [+animado] do Causativo.

Considerando o papel da percepção, essencialmente interpretativa, em que entram fatores como memória, focalização e proeminência, ligadas à atenção, temos que, na conceitualização de um evento dinâmico, o grau de saliência das entidades envolvidas, ligado ao traço [+animado], influencia no tipo de construção usada para codificar determinado construto.

A passiva é uma construção usada diante de duas entidades igualmente salientes do ponto de vista perceptual, da realidade objetiva. Afinal, tanto o SN Afetado como o SN Causativo da passiva representam entidades humanas. A escolha de uma codificação passiva para eventos em que as duas entidades são igualmente proeminentes do ponto de vista da hierarquia da empatia depende, portanto, da perspectivação, ou seja, do ponto de vista escolhido para construir a cena, do participante escolhido como trajector, como Figura. O fato foi observado por Camacho (2002) diante da significativa frequência de entidades humanas como sujeito da passiva, embora, em seus dados, entidades humanas não tenham sido predominantes. Os dados da CGE ressaltam o papel da perspectivação na passiva, ao apresentar predominância de entidades humanas nos dois participantes. 
Enquanto na passiva nos deparamos com entidades cognitivamente salientes no papel de Afetado e de Causativo, na impessoal, a saliência cognitiva maior é do Causativo. O Afetado é predominantemente inanimado; já o Causativo, humano. Há, portanto, uma inversão do fluxo natural, em que, normalmente, a entidade humana é selecionada como ponto de partida e a entidade inanimada como ponto de chegada. Noutros termos, como Figura e Fundo, respectivamente. Todavia, o SN que figura nas construções impessoais, embora sintaticamente possa representar um sujeito na impessoal clítica (considerandose a concordância verbal), mantém traços de objeto, seja pela posição, seja pelo estatuto informacional, seja pelo traço [-animado]. Na impessoal, o Causativo, embora represente uma entidade humana, é desfocalizado em favor do evento, predominantemente genérico, não-especificado, de valor habitual. A construção impessoal, assim, é usada em discursos genéricos, em que o Afetado, embora de baixa saliência, é tópico secundário, e o Causativo é extremamente pressuposto. Daí ser deixado inespecificado.

A construção média representa o oposto da impessoal. É a construção usada quando a entidade afetada é altamente saliente, e a entidade causativa, pouco saliente ou tida como inexistente. A entidade humana afetada, mais proeminente cognitivamente, é selecionada como sujeito. A entidade causativa, mais abstrata, perceptualmente menos saliente, é deixada totalmente inespecificada, o que leva à concepção do evento como espontâneo.

As diferenças entre as três construções se evidenciam quando se comparam exemplos com mesmo predicado, como os transcritos a seguir.

\section{(36) Passiva e média clítica}

a. a cidade de Tallaveyra foy acabada, sempre se defendeu per sua boa obra. (CGE-32)

b. E aqui se acabou o reyno dos Estrogodos de todo. (CGE-122)

(37) Passiva e impessoal

a. el rey Allarigo fora morto por el rey Clodoveo. (CGE-104)

b. E foy hi morto o emperador Almycal. (CGE-51)

c. E enno seu termho mata $\sim$ hu $\sim \mathrm{u} \sim$ peixe que ha nome alffarida. (CGE-40)

(38) Passiva e média perifrástica

a. ca no tan solamente forom departidos em a linguagem ${ }^{9}$... (CGE2)

\footnotetext{
${ }^{9}$ Glosa: 'Pois não apenas foram separados pela linguagem'.
} 
b. E desta guysa ficou o senhorio dos Suevos departido em duas partes $^{10}$. (CGE-93)

A saliência do Causativo, baseada na percepção e distinguibilidade entre os participantes e medida conforme o tipo de causa, está representada no gráfico 3. A passiva, cujo Causativo é frequentemente externo concreto percebido, e a impessoal, com alta predominância de Causativo externo identificável, apresentam Causativos com alta saliência. Há, portanto, maior distinguibilidade entre os participantes da passiva e da impessoal, o que as torna mais causativas. Já o Causativo da média, predominantemente interno, apresenta baixa saliência. Além disso, as ocorrências de saliência zero são mais frequentes na média, o que demonstra o baixo grau de causalidade desta construção. Esses resultados confirmam ainda a hipótese de que se o evento for espontâneo, então preferencialmente haverá construção média.

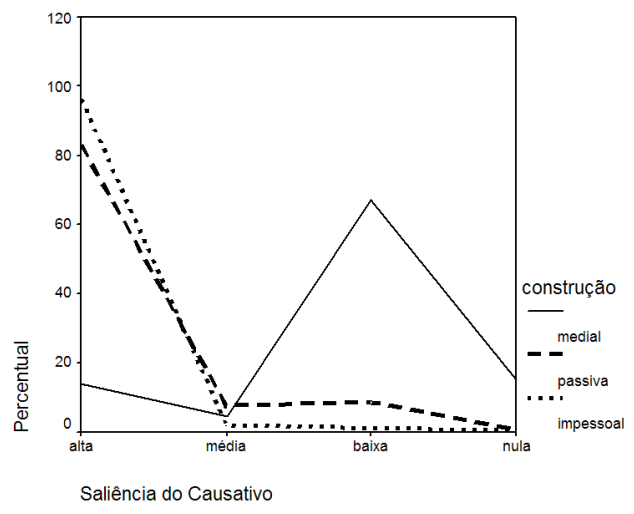

Gráfico 3. Grau de saliência do Causativo.

\subsection{O continuum da causalidade}

A fim de propor uma escala geral de causalidade ${ }^{11}$, tomemos as frequências do grau de transitividade e do grau de saliência do Causativo, considerando

\footnotetext{
${ }^{10}$ Glosa: E desta forma ficou o senhorio dos Suevos dividido em duas partes'.

${ }^{11}$ Usamos aqui a expressão "Escala de Causalidade", quando estamos tratando de construções de não-atribuição de causalidade. Esta aparente contradição advém do fato de Causalidade e não-atribuição de causalidade serem extremos de um mesmo continuum.
} 
que, quanto menor o grau de transitividade e de saliência do Causativo, menor o grau de causalidade, e vice-versa, quanto maior a transitividade e a saliência do Causativo, maior o grau de causalidade.

O quadro geral do grau de transitividade de cada construção e seus subtipos está exposto na tabela 2, a seguir. Nela, observamos que apenas a passiva, com alta transitividade, se sobressai. Todos os demais tipos apresentam predominância de média transitividade, o que surpreende em se tratando de construções consideradas de-transitivas, por definição, construções de baixa transitividade. Deve-se levar em conta, porém, que a transitividade é uma questão de grau, e ainda, que não foram avaliados todos os parâmetros de transitividade de Hopper e Thompson (1980). Assim, concluir que a passiva apresenta alta transitividade pode ser tão surpreendente quanto observar que uma construção tradicionalmente intransitiva é mais transitiva que uma transitiva tradicional. Trata-se, pois, de um resultado natural do fato de ser a transitividade uma propriedade escalar e de as referidas construções pertencerem a um mesmo continuum de causalidade como argumentamos.

\begin{tabular}{|c|c|c|c|c|c|c|}
\hline & & & \multicolumn{3}{|c|}{ Grau de Transitividade } & \multirow[b]{2}{*}{ Total } \\
\hline & & & alta & média & baixa & \\
\hline \multirow{12}{*}{ construção } & \multirow{2}{*}{ passiva } & $\mathrm{N}^{\circ}$ & 323 & 132 & 25 & 480 \\
\hline & & $\%$ & $67,3 \%$ & $27,5 \%$ & $5,2 \%$ & $100,0 \%$ \\
\hline & \multirow{2}{*}{ média clítica } & $\mathrm{N}^{\circ}$ & 4 & 61 & 17 & 82 \\
\hline & & $\%$ & $4,9 \%$ & $74,4 \%$ & $20,7 \%$ & $100,0 \%$ \\
\hline & \multirow{2}{*}{ média nào-clítica } & $\mathrm{N}^{\circ}$ & 3 & 207 & 21 & 231 \\
\hline & & $\%$ & $1,3 \%$ & $89,6 \%$ & $9,1 \%$ & $100,0 \%$ \\
\hline & \multirow{2}{*}{ média perifrástica } & $\mathrm{N}^{\circ}$ & 9 & 58 & 2 & 69 \\
\hline & & $\%$ & $13,0 \%$ & $84,1 \%$ & $2,9 \%$ & $100,0 \%$ \\
\hline & \multirow{2}{*}{ impessoal clítica } & $\mathrm{N}^{\circ}$ & 1 & 15 & 12 & 28 \\
\hline & & $\%$ & $3,6 \%$ & $53,6 \%$ & $42,9 \%$ & $100,0 \%$ \\
\hline & \multirow{2}{*}{ impessoal n-clítica } & $\mathrm{N}^{\circ}$ & 25 & 136 & 10 & 171 \\
\hline & & $\%$ & $14,6 \%$ & $79,5 \%$ & $5,8 \%$ & $100,0 \%$ \\
\hline \multirow{2}{*}{\multicolumn{2}{|c|}{ Total }} & $\mathrm{N}^{\circ}$ & 365 & 609 & 87 & 1061 \\
\hline & & $\%$ & $34,4 \%$ & $57,4 \%$ & $8,2 \%$ & $100,0 \%$ \\
\hline
\end{tabular}

Tabela 2. Grau de transitividade.

Quanto à saliência do Causativo, destacam-se as médias, que têm predominantemente Causativo com baixa saliência. As demais construções apresentam Causativos com alta saliência, conforme demonstra a tabela 3 . 


\begin{tabular}{|c|c|c|c|c|c|c|c|}
\hline & & & \multicolumn{4}{|c|}{ Saliência do Causativo } & \multirow[b]{2}{*}{ Total } \\
\hline & & & alta & média & baixa & nula & \\
\hline \multirow{12}{*}{ construção } & \multirow{2}{*}{ passiva } & $\mathrm{N}^{\circ}$ & 399 & 36 & 41 & 4 & 480 \\
\hline & & $\%$ & $83,1 \%$ & $7,5 \%$ & $8,5 \%$ &, $8 \%$ & $100,0 \%$ \\
\hline & \multirow{2}{*}{ média clítica } & $\mathrm{N}^{\circ}$ & 13 & 6 & 45 & 18 & 82 \\
\hline & & $\%$ & $15,9 \%$ & $7,3 \%$ & $54,9 \%$ & $22,0 \%$ & $100,0 \%$ \\
\hline & \multirow{2}{*}{ média não-clítica } & $\mathrm{N}^{\circ}$ & 26 & 10 & 163 & 32 & 231 \\
\hline & & $\%$ & $11,3 \%$ & $4,3 \%$ & $70,6 \%$ & $13,9 \%$ & $100,0 \%$ \\
\hline & \multirow{2}{*}{ média perifrástica } & $\mathrm{N}^{\circ}$ & 14 & & 48 & 7 & 69 \\
\hline & & $\%$ & $20,3 \%$ & & $69,6 \%$ & $10,1 \%$ & $100,0 \%$ \\
\hline & \multirow{2}{*}{ impessoal clítica } & $\mathrm{N}^{\circ}$ & 23 & 2 & 2 & 1 & 28 \\
\hline & & $\%$ & $82,1 \%$ & $7,1 \%$ & $7,1 \%$ & $3,6 \%$ & $100,0 \%$ \\
\hline & \multirow{2}{*}{ impessoal n-clític: } & $\mathrm{N}^{\circ}$ & 169 & 2 & & & 171 \\
\hline & & $\%$ & $98,8 \%$ & $1,2 \%$ & & & $100,0 \%$ \\
\hline \multirow{2}{*}{\multicolumn{2}{|c|}{ Total }} & $\mathrm{N}^{\circ}$ & 644 & 56 & 299 & 62 & 1061 \\
\hline & & $\%$ & $60,7 \%$ & $5,3 \%$ & $28,2 \%$ & $5,8 \%$ & $100,0 \%$ \\
\hline
\end{tabular}

Tabela 3. Grau de saliência do Causativo.

A fim de hierarquizarmos as construções, conjugamos os dois parâmetros transitividade e saliência do Causativo, atribuindo, a medida 2 quando há predomínio do grau alto; medida 1, quando predomina grau médio; e medida 0, quando predomina grau baixo. Assim, a passiva, em que predominam ocorrências de alta transitividade $(72,1 \%)$ e alta saliência do Causativo (83\%), receberá medida 2 nos dois parâmetros, resultando em grau de Causalidade 4, quando se conjugam as duas medidas. Já as construções médias, por apresentarem predominância de grau médio de transitividade e apresentarem maior frequência de Causativo com baixa ou nula saliência, recebem medida 1 no parâmetro Grau de Transitividade e medida 0 no parâmetro Grau de saliência do Causativo, resultando em grau de Causalidade 1. O resultado geral está demonstrado no Quadro 1 a seguir.

\begin{tabular}{rccc}
\hline & Transitividade & Saliência & Causalidade \\
\hline Passiva & alta & alta & 4 \\
Impessoal não-clítica & média & alta & 3 \\
\hline Impessoal clítica & média & alta & 3 \\
Media perifrástica & média & baixa & 1 \\
\hline Media não-clítica & média & baixa & 1 \\
\hline Media clítica & média & baixa & 1 \\
\hline
\end{tabular}

Quadro 1. Grau de causalidade das construções

Como mostra o Quadro 1, os subtipos de impessoal e de média apresentam comportamento semelhante quanto aos graus de transitividade e de saliência cognitiva, que se reflete em um mesmo grau de causalidade. Se por um lado isso justifica serem agrupadas como uma mesma construção - impessoal ou 
média -, por outro mascara as diferenças que há entre elas. Na verdade, embora haja predominância de média transitividade nos dois tipos de impessoal, a impessoal não-clítica é, entre as impessoais, a que apresenta mais ocorrências de alta transitividade e a que não apresenta nenhuma ocorrência de baixa ou nula saliência. Portanto, é mais causal que a impessoal clítica.

Entre as médias, a média clítica é a que apresenta maior número de ocorrências em que o Causativo é inconcebível, isto é, o evento é dado como espontâneo, e maior número de ocorrências com baixa transitividade. A perifrástica é a que apresenta menor número de Causativos inconcebíveis e a que mostra mais ocorrências de Causativos altamente salientes. É também, entre as médias, a que apresenta maior número de ocorrências com alta transitividade. Já a não-clítica é intermediária quanto ao Causativo inconcebível, mas apresenta maior número de Causativo de baixíssima saliência e menor número de Causativos com altíssima saliência. Destarte, as construções médias podem ser assim hierarquizadas, da mais causal para a menos causal:

média perifrástica $>$ média não-clítica $>$ média clítica.

Por fim, agrupando as escalas de cada construção, conforme a hierarquia do quadro, temos a seguinte escala de causalidade, que apresenta no topo a construção passiva, como a mais causal dentre as construções de não-atribuição de causalidade, ou seja, como a construção mais próxima da transitiva ativa canônica, e na base da escala, como menos causal, a construção média clítica ${ }^{12}$.

\section{escala de causalidade}

+ causal

passiva

impessoal não-clítica

impessoal clítica

média perifrástica

média não-clítica

média clítica

- causal

${ }^{12}$ É preciso reforçar que a escala de causalidade proposta em (39) restringe-se às construções estudadas, todas formas de expressão de não-atribuição de causalidade. Uma escala de causalidade completa deveria mostrar no extremo superior como mais causal que a passiva a construção ativa prototípica, de que é exemplo a frase (1), anteriormente comentada. 
A média clítica configura-se, portanto, como a construção prototípica do domínio funcional não-atribuição de causalidade, por apresentar menor grau de causalidade, como ilustrada na escala em (39), e codificar, mais do que qualquer outra, eventos espontâneos. Considerando que médias e passivas situam-se nos extremos da escala de causalidade, os dados nos permitem fazer a seguinte predição, ao nível de 78\%: se houver não-atribuição de causalidade, mais provavelmente haverá construções médias e menos provavelmente haverá construções passivas ou impessoais. É o que mostra o gráfico a seguir, em que observamos uma predominância de construções médias quando não podemos identificar um Causativo para o evento, seja porque este é, de fato, nãoprovocado, seja porque é conceitualizado como tal.

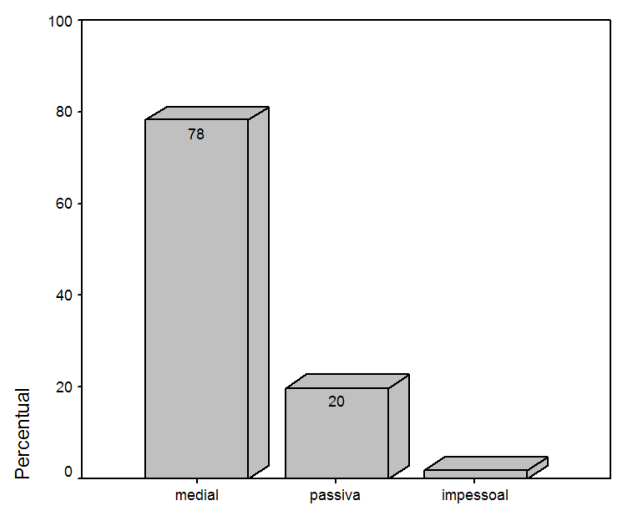

Gráfico 4. Frequência de Causativo não-identificável.

Se a predição for para eventos de fato espontâneos, a predição é ainda mais forte, da função para a forma: $96 \%$ dos eventos não-provocados são codificados pela média. Os $4 \%$ codificados por passiva ou impessoal correspondem a eventos de percepção e de cognição, em que o experienciador vivencia a experiência sem contribuir ativamente para ela, ou seja, o estímulo chega a ele sem que, para isso, ele contribua com a intenção, como ver, esquecer, a depender do contexto, como nos exemplos a seguir:

(40) E ainda e o termo de Raya ha outro castello que he atalaya sobre o mar, ca elle jaz e $\sim$ tal logar que no pode pello mar vi i $\sim$ r cousa pequena nem grande pera Spanha que delle nom vejam. (CGE-46)

(41) e juntou muy gra de hoste e foy co tra os Roma a as e soubeo fazer per tal guysa que elles no forom percebudos delle se no tarde. (CGE-58) 


\section{Considerações Finais}

Partindo do princípio de que passivas, impessoais e médias codificam um mesmo domínio funcional, concluímos que a média é a mais prototípica das construções de não-atribuição de causalidade, por ser a que apresenta Causativo menos saliente e menor grau de transitividade. Como construção prototípica da não-atribuição de causalidade, a média é a construção escolhida para codificar eventos espontâneos ou tidos como tais. Já a passiva, embora também seja uma forma de expressão da não-atribuição de causalidade, se afastou do protótipo de não-atribuição de causalidade, por seu Causativo ser frequentemente evocado e apresentar maior grau de transitividade. Aproximase, portanto, da construção ativa prototípica que apresenta alta transitividade. Do mesmo modo, a impessoal, cujo Causativo é frequentemente inferível, manifestou-se como mais causativa e mais transitiva que a média.

$\mathrm{Na}$ escala geral de causalidade que ordena os subtipos das construções, a média perifrástica se aproximou das construções mais causativas, tanto pelo grau de transitividade quanto pela saliência do Causativo, o que explica a oscilação, comum na literatura, em considerá-la passiva ou medial.

Em suma, os resultados demonstram que as construções passiva, impessoal e média pertencem a um mesmo domínio funcional, a não-atribuição de causalidade. Entretanto, não são formas diferentes de dizer a mesma coisa. São codificações diferentes que refletem distintas conceitualizações de um evento de mudança.

\section{Referências}

CAMACHO, Roberto. A gradação tipológica das construções de voz. Revista Gragoatá. Niterói, n. 21. pp.167-189, 2006.

CAMACHO, Roberto. Construções de voz. In: ABAURRE, Maria Bernadete e RODRIGUES, Ângela C.S. (orgs) Gramática do português falado. Campinas:Editora da Unicamp. pp.227-316, 2002.

CAMACHO, Roberto Gomes. Em defesa da categoria de voz média no português. DELTA, São Paulo, v. 19, n. 1, 2003 . Disponível em <http://www.scielo.br/scielo.php?script $=\mathrm{sci}_{a}$ rttext\&pid=S010244502003000100004\&lng $=$ pt\&nrm $=$ iso $>$. acessos em 13 fev. 2013. http://dx.doi.org/10.1590/S0102-44502003000100004.

CINTRA, Luís Filipe Lindley (ed.). Crónica Geral de Espanha de 1344. edição crítica. Lisboa, Academia de Ciências, 1951. Disponível em $<$ http://purl.pt/336>. Acesso em 30 set. 2012. 
COMRIE, Bernard. Aspect: na introduction to the study of verbal aspect and related problems. London: Cambrigde University Press, 1978.

CRÓNICA GERAL DE ESPANHA de 1344 / versão digitalizada a partir da edição crítica do texto português por Luís Filipe Lindley Cintra. - Lisboa: Academia Portuguesa da História, 1951-1961. - 3 v.; 26 Tese dout. em Filologia Românica, Univ. de Lisboa, 1953. Disponível em <http://cipm.fcsh.unl.pt/>. Acesso em 30 set. 2012.

GIVÓN, T. English grammar: a function-based introduction. Amsterdam: John Benjamins. v.1, 1993.

GIVÓN, T. Context as other minds: the pragmatics of sociality, cognition and communication. Amsterdam/Philadelphia: John Benjamins Publishing Company. 2005.

GIVÓN, T. Syntax: an introduction. Amsterdam/Philadelphia: John Benjamins Publishing Company, 2001.

HOPPER, P. J. e THOMPSON, S. A. Transitivity in grammar and discourse, Language, vol. 56. Baltimore, 1980.

KEMMER, Suzannne. The middle voice. Amsterdam/Philadelphia: John Benjamins, 1993.

LANGACKER, Ronald W. Foundations of cognitive grammar: theoretical prerequisites. Stanford, California: Stanford University Press. v.1, 1987.

LANGACKER, Ronald. Foundations of cognitive grammar. Descriptive application. Stanford/California: Stanford University Press. 1991.

MATTOS E SILVA, Rosa Virgínia. Estruturas trecentistas: elementos para uma gramática do Português Arcaico.Lisboa:Imprensa Nacional-Casa da Moeda, 1989.

PRINCE, E. Toward a taxonomy of given/new information in: P. COLE (ed.) Radical pragmatics. New York, 1981.

Recebido em: 16/05/2012

Aceito em: 13/09/2012 